\title{
Arthroscopic Treatment of Perilunate Dislocations and Fracture Dislocations
}

\author{
Jong Pil Kim, $\mathrm{MD}^{1,2}$ Jae Sung Lee, $\mathrm{MD}^{3}$ Min Jong Park, $\mathrm{MD}^{4}$
}

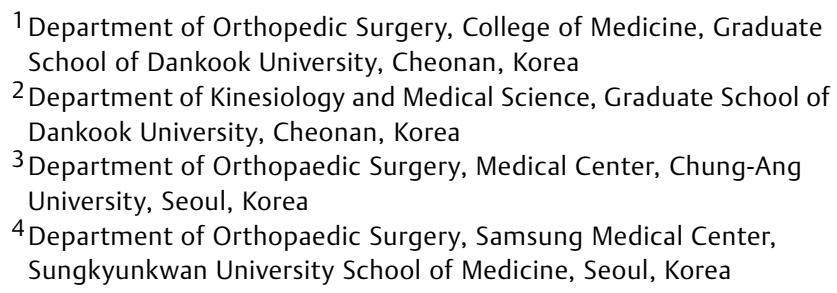

\begin{abstract}
Address for correspondence Min Jong Park, MD, Department of Orthopaedic Surgery, Samsung Medical Center, Sungkyunkwan University School of Medicine, 50 Irwon-dong, Gangnam-gu, Seoul 135-710, Korea (e-mail: mjp3506@skku.edu).
\end{abstract}

J Wrist Surg 2015;4:81-87.

\begin{abstract}
Background The key to a successful result in the treatment of perilunate dislocations (PLDs) and fracture-dislocations (PLFDs) is the restoration of normal alignment of the carpal bones, followed by stable maintenance until healing. This article aimed to assess whether arthroscopic techniques are a reliable surgical option for the treatment of this challenging injury.

Materials and Methods Twenty patients with an acute PLD or PLFD were treated by an arthroscopic technique. They were retrospectively reviewed at an average follow-up of 31.2 months (range 18-61 months). Functional outcomes were assessed with the Modified Mayo Wrist Score (MMWS), Disabilities of the Arm, Shoulder, and Hand (DASH) questionnaire, and Patient-Rated Wrist Evaluation (PRWE) score as well as radiographic evaluations.

Description of Technique Arthroscopic reduction and percutaneous fixation was performed to the scapholunate and lunotriquetral intervals using Kirschner wires (Kwires) as joysticks as well as to the scaphoid using a cannulated headless screw for transscaphoid-type injuries. The K-wires were removed at 10 weeks postoperation.

Results Overall functional outcomes according to the MMWS were rated as excellent in three patients, good in eight, fair in seven, and poor in two. The mean DASH score was 18, and the mean PRWE score was 30 . On the basis of radiographic parameters,

\section{Keywords}

- arthroscopy

- perilunate

- dislocation

- fracture-dislocation

- percutaneous reduction obtained at the operation was maintained within normal ranges in 15 patients. No patient had developed arthritis by the last follow-up.

Conclusions The medium-term results show that arthroscopic treatment can provide proper restoration and stable fixation of carpal alignment and results in satisfactory functional and radiologic outcomes for acute perilunate injuries.

Level of Evidence Level IV.
\end{abstract}

Perilunate injuries are highly unstable carpal dissociations characterized by a complete loss of contact between the lunate and surrounding carpal bones. They can be pure perilunate dislocations (PLDs) or perilunate fracture-dislocations (PLFDs) associated with carpal fractures around the lunate. $^{1-4}$ The key to successful treatment of perilunate injuries is early surgical intervention to restore normal alignment of the carpal bones and stability. ${ }^{3,5}$ Generally accepted treatment has consisted of open primary repair or reconstruction of the ligaments with open reduction and 
internal fixation of the fractures. ${ }^{1,3,6-12}$ However, it is clear that open surgery introduces additional surgical trauma to the important capsular and ligamentous structures, which may be associated with a high rate of complications, such as the development of joint stiffness due to capsular fibrosis or failure of proper bone healing because of damage to the blood supply. ${ }^{4,7}$ Furthermore, posttraumatic arthritis, which may modify the functional outcome, is major concern following the open surgery, with an incidence of $38-86 \%$. $3,4,13$

Arthroscopic technique has the theoretical advantage of facilitating the healing of fractures and torn ligaments because it can minimize capsular and adjacent soft tissue injury and provide preservation of an already tenuous blood supply. ${ }^{14-17}$ In fact, several pioneers suggested that an arthroscopic reduction and percutaneous fixation, as an alternative to an open approach, can effectively treat acute perilunate injuries. ${ }^{12,18}$ We propose that arthroscopic treatment results in successful restoration of carpal alignment and good functional outcomes, and this technique can be a reliable option for the treatment of these challenging injuries.

\section{Patients and Methods}

A retrospective review of 20 patients with a PLD or PLFD who were treated with arthroscopic reduction and percutaneous fixation has been performed and reported. ${ }^{19}$ According to the sagittal displacement classification system described by Herzberg, ${ }^{3}$ there were seven stage I (the lunate remained in place under the radius), ten stage IIa (the lunate was palmarly dislocated but rotated by less than $90^{\circ}$ ), and three stage IIb (the lunate was palmarly dislocated and rotated more than $90^{\circ}$ ). Our series included five PLDs, 12 transscaphoid PLFDs, and three transscaphoid, transtriquetral PLFDs. There were 19 male patients and one female patient with a mean age of 37.3 years (range 19-57 years). The dominant wrist was involved in eight patients. Fifteen patients sustained an injury during falls from a height onto the outstretched hand. Three injuries were caused by motorcycle accidents, and the remaining two injuries occurred during snowboarding. The median time from the injury to operation was 3.9 days (range 1-20 days). Sixteen patients underwent the surgery within the first week following the accident. Six patients had concomitant extremity injuries: one olecranon fracture in the same side, two distal radius fractures with or without elbow fracture-dislocation in the contralateral side, and three lower extremity fractures including an intertrochanteric fracture, a patellar fracture, and a calcaneal fracture.

All patients were assessed postoperatively with Disabilities of the Arm, Shoulder, and Hand (DASH) questionnaire ${ }^{20}$ and Patient Related Wrist Evaluation (PRWE) scores $^{21}$ as well as clinical examination, such as range of motion and grip strength. Overall outcomes were assessed according to the Modified Mayo Wrist Score (MMWS) system, of which rating of this system was divided by four categories as follows: excellent, $90-100$ points; good, $80-89$ points; fair, $65-79$, and poor, less than 65 points. ${ }^{1}$

Radiographs were evaluated by measuring the scapholunate gap, the lunotriquetral gap, the scapholunate angle, and the carpal height ratio at the time of surgery and at the last follow-up examination. ${ }^{22,23}$ Midcarpal and radiocarpal arthritis were rated based on plain radiographs according to the system of Knirk and Jupiter. ${ }^{24}$

\section{Surgical Technique}

Before arthroscopy was performed, a closed reduction had been attempted. When the gross reduction was not amenable to initial closed reduction, this maneuver was not repeated in order to prevent further cartilage or soft tissue damage. Fifteen of 20 patients (75\%) achieved a gross reduction of the capitolunate joint by manipulation. The other five patients failed the gross reduction.

Wrist arthroscopy was performed under brachial plexus block or general anesthesia. The hand was suspended using a Traction Tower (Linvatec, Largo, FL, USA) with 10 to $15 \mathrm{lb}$ of traction. The forearm was wrapped with a compressive elastic bandage, and continuous saline irrigation was instilled by gravity infusion from an elevated bag to minimize fluid extravasation. After clot and debris were removed through the 3-4 and 4-5 portals, the palmar capsular ligaments, scapholunate and lunotriquetral ligaments, and triangular fibrocartilage complex (TFCC) were carefully evaluated. Arthroscopic findings of five patients who had failed to achieve a gross reduction by a closed manipulation revealed that palmar capsular ligaments were torn and interposed between the lunate and capitate (-Figs. 1a-g). In those cases, the lunate, which had volarly dislocated with or without proximal fragment of the scaphoid, was effectively reduced by pulling it or them dorsally with use of a probe (Video 1). Extensive injury to the radioscaphocapitate ligament with relatively intact long and short radiolunate ligaments was the consistent finding, which can be explained anatomically based on the pathology of perilunate injury.

After evaluation of the radiocarpal joint, our attention was directed toward the midcarpal joint, in which the main disruption had occurred. The midcarpal space was entered at the midcarpal radial (MCR) and midcarpal ulnar (MCU) portals. Bone or cartilage fragments and frayed edges of torn palmar capsular ligaments were thoroughly débrided or removed to facilitate reduction of the proximal intercarpal joint (-Fig. 2a-f). Arthroscopic evaluation of the midcarpal joint showed focal cartilage damage of the capitate in nine wrists and volar rim fracture of the lunate in seven wrists. Probing the intercarpal joint of the proximal carpal row showed gross instability of both the scapholunate and lunotriquetral articulations in PLDs and the lunotriquetral joint in transscaphoid PLFDs from the complete tear. Six of 15 patients with transscaphoid injuries showed combined scapholunate ligamentous injuries graded as II or III according to the classification suggested by Geissler et al. ${ }^{25}$

Once the injury pattern was identified, Kirschner wires (K-wires) were inserted percutaneously into the scaphoid and triquetrum and an additional K-wire placed dorsally into the lunate under a fluoroscope (-Fig. 1d). After longitudinal traction was released, the scapholunate and lunotriquetral intervals were reduced by manipulating the K-wires as joysticks, as viewed directly in the midcarpal portals (-Fig. 1e). 

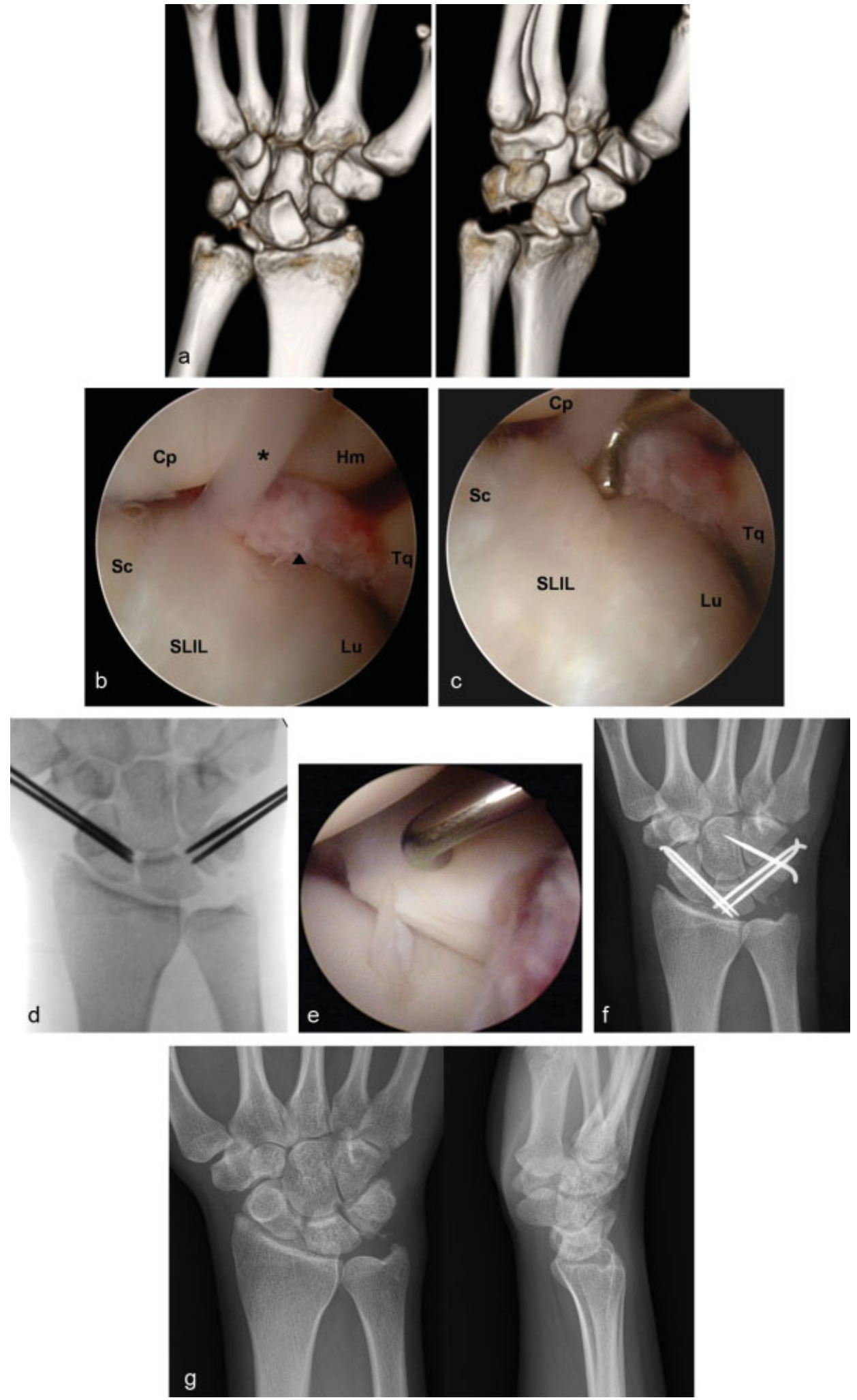

Fig. 1 (a) Three-dimensional CT images of a 20-year-old woman who had failed to achieve a gross reduction by a closed manipulation showed volar dislocation of the lunate. (b,c) Arthroscopic findings showing that palmar capsular ligaments were torn and interposed between the lunate and capitate (arrowhead), which was reduced by pulling the lunate with use of a probe. Asterisk indicates the dorsal capsular tissue attached to the dorsal limb of the lunate. (d-f) The scapholunate and lunotriquetral intervals were reduced by manipulating K-wires, which were inserted percutaneously into the scaphoid and triquetrum, as viewed directly in the midcarpal portals. The wires were driven across the intercarpal intervals into the lunate once the anatomic reduction was achieved. (g) Eighteen-month follow-up radiographs showing a normal carpal alignment with no evidence of arthritis. (Cp, capitates; Hm, hamate; Lu, lunate; Sc, scaphoid; SLIL, scapholunate interosseous ligament;Tq, triquetrum). 

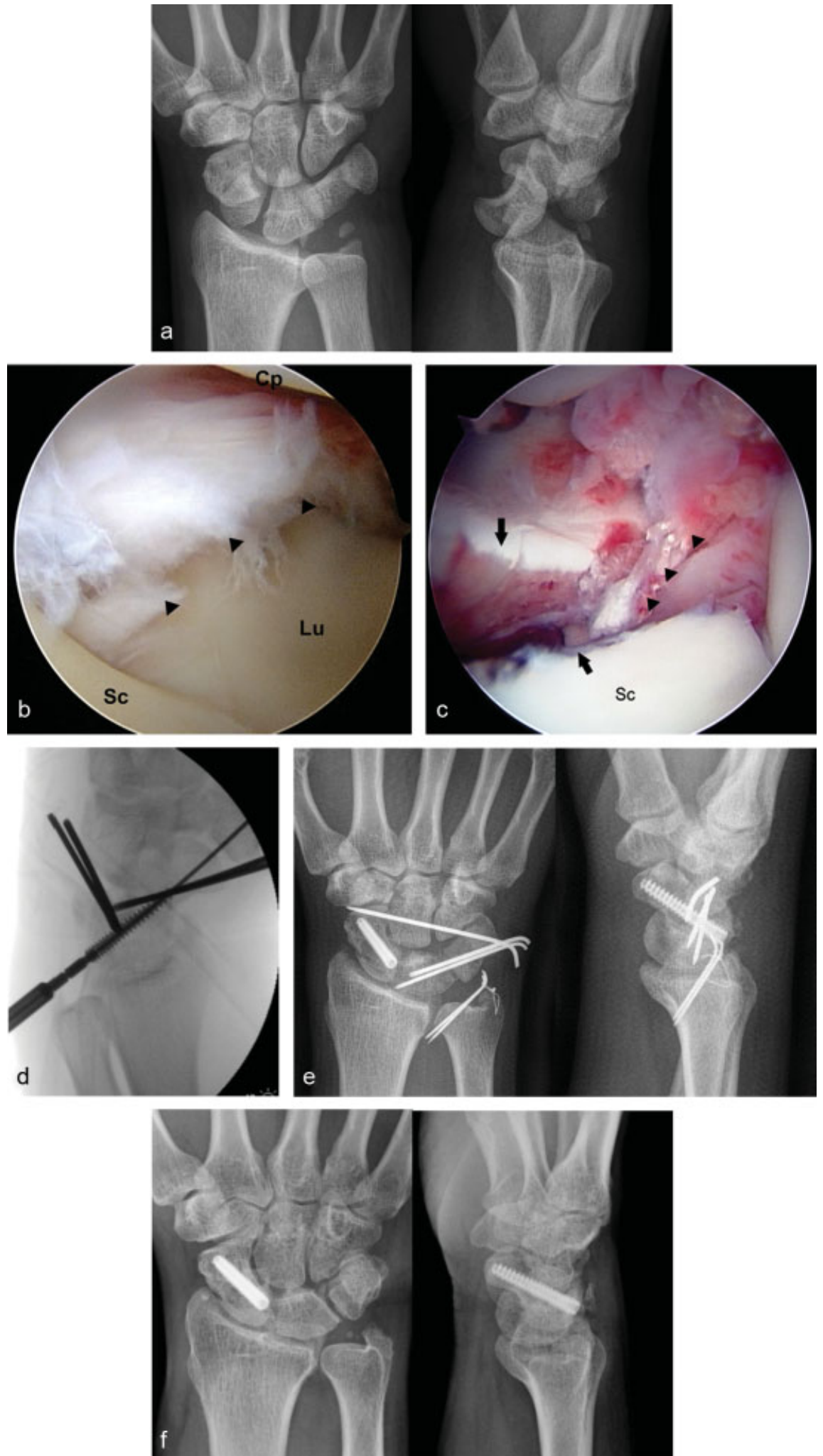

Fig. 2 (a) Initial radiographs of a 38-year-old man showing a transscaphoid transtriquetral PLFD. (b,c) Midcarpal view showing torn palmar capsular ligaments (arrowheads) that were interposed between the carpal rows and between the fracture fragments of the scaphoid (arrows). (d,e) After accurate reduction was obtained by manipulating K-wires and advancing these wires across the fracture site, a scaphoid screw was percutaneously inserted as well as K-wires into the triquetrum and capitate. (f) Twenty-six-month follow-up radiographs showing union of fractures with no evidence of arthritis (Cp, capitate; Lu, lunate; Sc, scaphoid). 
When the anatomic reduction was restored, the wires were then driven across the intercarpal intervals into the lunate (-Fig. 1f).

For transscaphoid-type injuries, the reduction of the scaphoid fragments was attempted by manipulating provisional K-wires driven into the distal fragment and not across the fracture site, and an additional K-wire placed on the dorsum of the proximal pole of the scaphoid. These wires were used as joysticks to reduce the fracture further anatomically, while viewing the articular surface from the midcarpal portal. K-wires in the distal pole of the scaphoid were advanced across the fracture site into the proximal fragment after a congruous articular surface was obtained. Percutaneous scaphoid fixation using a cannulated headless autocompression screw (Acutrak; Acumed, Beaverton, OR, USA) was attempted in 11 patients who did not have comminution in the scaphoid. The Acutrak screw was introduced after a guide wire was properly advanced from dorsal to volar along the central axis of the scaphoid under fluoroscopic control, as described by Slade et al (-Fig. 2d). ${ }^{26}$ The patients who had combined intercarpal ligamentous injuries had additional $1.2-\mathrm{mm} \mathrm{K}$-wire fixation into the intercarpal joint under arthroscopic assistance. Finally, the wires were bent, cut, and buried underneath the skin ( - Fig. 2e).

After the operation, the wrist was immobilized in a shortarm thumb spica cast. In pure ligamentous injuries, the K-wires were removed at 10 weeks. In patients with a scaphoid fracture that had been fixed with K-wires, the Kwires were removed when there was radiographic evidence of a union. Intensive physiotherapy was started.

\section{Results}

Acute carpal tunnel syndrome developed in 8 patients (40\%) following the injury. The symptoms resolved within 48 hours after arthroscopic reduction, and no patient required release of the transverse carpal ligament. Besides the failed union of scaphoid fractures, there were no conspicuous complications, except skin irritation by the buried pins in two patients, which resolved after the pin was removed.

The average time to scaphoid union in transscaphoid injuries was 14 weeks (range 9-21 weeks) except in two patients with nonunion. Of the two nonuions, one patient, who had a transscaphoid, transtriquetral PLFD and underwent surgery 20 days after injury, showed loss of the carpal alignment with an avascular change of the proximal fragment of the scaphoid at 6-month follow-up evaluation; a scaphoid excision and four-corner fusion was subsequently performed. The other patient, who had had a transscaphoid PLFD, demonstrated nonunion from the computed tomography (CT) perspective at 12 months after the surgery. No further treatment was performed for this patient because he did not complain of wrist pain or functional disability.

The mean follow-up period was 31.2 months (range 18-61 months). At the final evaluation, the average extension and flexion were $53^{\circ}$ (range $30-70^{\circ}$ ) and $51^{\circ}$ (range $25-70^{\circ}$ ), respectively. The average radial and ulnar deviation were $17^{\circ}$ (range $10-26^{\circ}$ ) and $30^{\circ}$ (range $18-42^{\circ}$ ), respectively. The average pronation and supination were $71^{\circ}$ (range 50-90 and $79^{\circ}$ (range $55-90^{\circ}$ ), respectively. The range of motion of the injured wrist ranged from $79 \%$ to $89 \%$ in comparison with the contralateral side ( - Fig. 3 ). The average grip strength was $78 \%$ (range $62-94 \%$ ) of the contralateral wrist. The mean DASH and PRWE outcome scores were 18 (range 1-36) and 30 (range 5-52), respectively. The overall functional outcomes according to the MMWS were excellent or good in 11 patients and fair or poor in 9 patients (-Fig. 4). The one patient who underwent a four-corner fusion with excision of the scaphoid was considered as having a poor result. The other patient who had a poor result developed a diffuse stiffness of the wrist and hand.

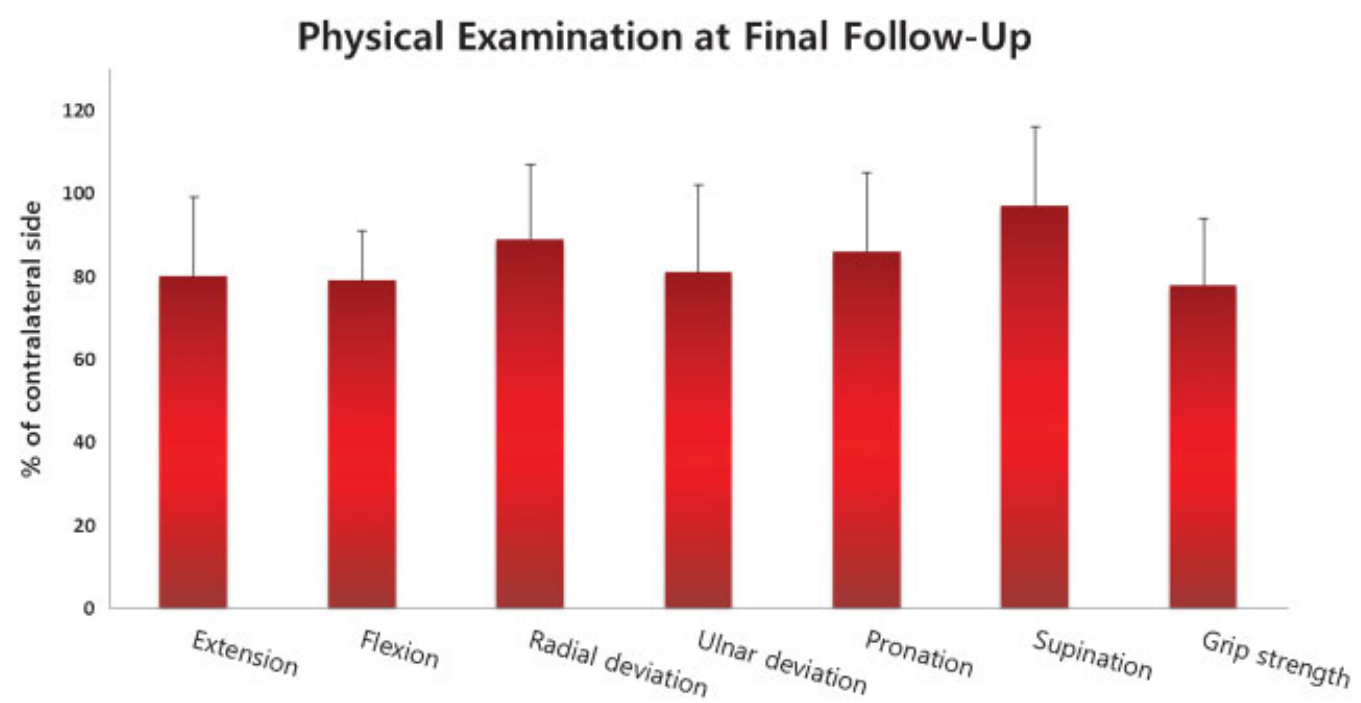

Fig. 3 Physical examination at final follow-up. 


\section{Overall Functional Outcomes}

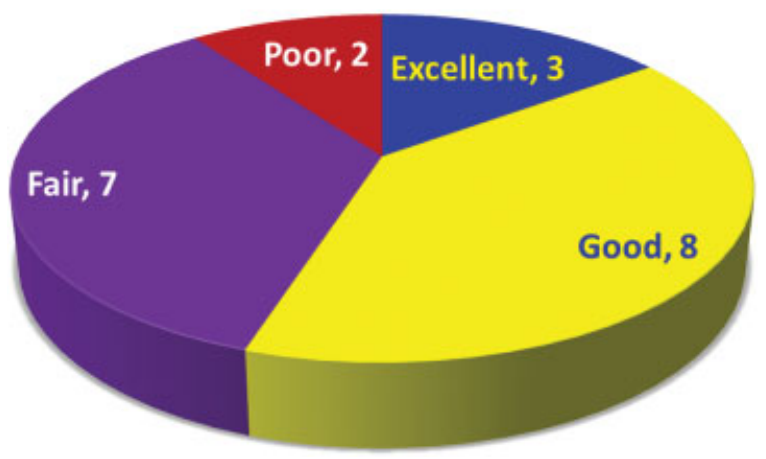

Fig. 4 Overall functional outcomes according to the MMWS.

Radiologic measurements are summarized in -Table 1. There were significant radiologic changes in scapholunate gap, scapholunate angle, and carpal height at the final follow-up compared with those immediate postoperative measurement $(p=0.038 ; p<0.001$; and $p=0.038$, respectively). The scapholunate gap and scapholunate angle increased at final follow-up by mean $0.3 \mathrm{~mm}$ (range $0-0.9$ $\mathrm{mm}$ ) and $3^{\circ}\left(\right.$ range $\left.0-8^{\circ}\right)$. The average carpal height ratio had decreased by 0.02 (range 0-0.04). However, 15 patients had normal scapholunate angle (normal, 30$\left.60^{\circ}\right),{ }^{22}$ and 16 patients had normal carpal height ratio (normal $0.51-0.57)^{23}$ at final follow-up. No patients had radiographic evidence of arthritis of either radiocarpal or midcarpal joints.

\section{Discussion}

Most surgeons have suggested that the key to a successful long-term result in the treatment of a PLD or PLFD is open repair of interosseous and capsular ligaments and internal fixation of the fracture. ${ }^{6,7,27-29}$ Recently, arthroscopic techniques as an alternative minimally invasive method for the treatment of perilunate injuries have been suggested by several authors. ${ }^{12,18}$ They asserted that arthroscopic treatment allows anatomic reduction of intercarpal articulations and proper reestablishment of carpal stability; however, the results were based on only a few patients.
Our previous study has several limitations. It is a retrospective case series without a control group, and the number of subjects was relatively small with a heterogenous combination of pure dislocations and fracture-dislocations. In addition, this study includes an insufficient follow-up period to prove the efficacy of arthroscopic techniques in preventing the development of posttraumatic arthritis.

Souer et $\mathrm{al}^{30}$ evaluated 18 patients treated with open reduction followed by temporary intercarpal K-wire fixation or screw fixation at an average of 44 months. The average flexion-extension ranges of motion (ROMs) of the wrist and grip strength were $\sim 60 \%$ and $70 \%$ of the contralateral wrists, respectively. Four patients (22\%) had wrist arthrodesis due to a deep infection, scaphoid nonunion, crushing injury, or early development of arthritis. Forli et al ${ }^{13}$ reported on 11 patients with PLDs and 7 patients with transscaphoid PLFDs treated with open reduction and internal fixation. The mean flexionextension ROM and grip strength of the injured wrist were $76 \%$ and $87 \%$, respectively, compared with the contralateral side. They also observed signs of arthritis in 12 of 18 patients (67\%) with a minimum 10-year follow-up. Otherwise, several authors have demonstrated better results of an open approach where the average ROM of wrist flexion-extension and grip strength were as high as $80 \%$ of the uninjured opposite wrist. ${ }^{3,9,31}$ Therefore, the clinical results of our series seem to compare favorably with those of open techniques.

Our initial concern of the previous study was whether the proximal interosseous ligaments, which serve as the key stabilizers of the carpal joint, can achieve reliable healing that is sufficient to maintain carpal stability without a direct repair. The results of our study suggest that the capsular structures can heal adequately with a good vascularity when they are properly approximated and protected for some period and that open repair of interosseous ligaments is not necessary, given the additional soft tissue and vascular injuries. ${ }^{14-17}$ Therefore, we believe that arthroscopic management has the great advantage of facilitating the healing of fractures and torn ligaments since it can minimize capsular and adjacent soft tissue injury and provide preservation of an already tenuous blood supply. ${ }^{32-34}$

Table 1 Results of radiographic measurements after arthroscopic reduction and percutaneous fixation

\begin{tabular}{|l|l|l|l|}
\hline Parameter & Immediately after surgery & Follow-up & $p$ value \\
\hline Scapholunate gap $(\mathrm{mm})$ & $1.6(1.3$ to 2$)$ & $1.9(1.4$ to 2.6$)$ & 0.038 \\
\hline Lunotriquetral gap $(\mathrm{mm})$ & $1.7(1.3$ to 2.2$)$ & $1.8(1.3$ to 2.2$)$ & 0.295 \\
\hline Scapholunate angle $\left(^{\circ}\right)$ & $55(48$ to 61$)$ & $58(48$ to 64$)$ & $<0.001$ \\
\hline Carpal height & $0.54(0.52$ to 0.54$)$ & $0.52(0.49$ to 0.54$)$ & 0.038 \\
\hline
\end{tabular}




\section{Note}

A statement of the location where the work was performed (only if authors from multiple institutions): Department of Orthopaedic Surgery, Samsung Medical Center, Sungkyunkwan University School of Medicine, 50 Irwondong, Gangnam-gu, Seoul 135-710, Korea.

\section{Conflict of Interest}

None

\section{References}

1 Cooney WP, Bussey R, Dobyns JH, Linscheid RL. Difficult wrist fractures. Perilunate fracture-dislocations of the wrist. Clin Orthop Relat Res 1987;(214):136-147

2 Green DP, O'Brien ET. Classification and management of carpal dislocations. Clin Orthop Relat Res 1980;(149):55-72

3 Herzberg G, Forissier D. Acute dorsal trans-scaphoid perilunate fracture-dislocations: medium-term results. J Hand Surg $[\mathrm{Br}]$ 2002;27(6):498-502

4 Hildebrand KA, Ross DC, Patterson SD, Roth JH, MacDermid JC, King GJ. Dorsal perilunate dislocations and fracture-dislocations: questionnaire, clinical, and radiographic evaluation. J Hand Surg Am 2000;25(6):1069-1079

5 Kozin SH. Perilunate injuries: diagnosis and treatment. J Am Acad Orthop Surg 1998;6(2):114-120

6 Adkison JW, Chapman MW. Treatment of acute lunate and perilunate dislocations. Clin Orthop Relat Res 1982;(164):199-207

7 Budoff JE. Treatment of acute lunate and perilunate dislocations. J Hand Surg Am 2008;33(8):1424-1432

8 Green DP, O'Brien ET. Open reduction of carpal dislocations: indications and operative techniques. J Hand Surg Am 1978; 3(3):250-265

9 Knoll VD, Allan C, Trumble TE. Trans-scaphoid perilunate fracture dislocations: results of screw fixation of the scaphoid and lunotriquetral repair with a dorsal approach. J Hand Surg Am 2005; 30(6):1145-1152

10 Minami A, Kaneda K. Repair and/or reconstruction of scapholunate interosseous ligament in lunate and perilunate dislocations. J Hand Surg Am 1993;18(6):1099-1106

11 Sauder DJ, Athwal GS, Faber KJ, Roth JH. Perilunate injuries. Orthop Clin North Am 2007;38(2):279-288, vii vii

12 Weil WM, Slade JF III, Trumble TE. Open and arthroscopic treatment of perilunate injuries. Clin Orthop Relat Res 2006;445(445): 120-132

13 Forli A, Courvoisier A, Wimsey S, Corcella D, Moutet F. Perilunate dislocations and transscaphoid perilunate fracture-dislocations: a retrospective study with minimum ten-year follow-up. J Hand Surg Am 2010;35(1):62-68

14 Whipple TL. The role of arthroscopy in the treatment of scapholunate instability. Hand Clin 1995;11(1):37-40

15 Osterman AL, Seidman GD. The role of arthroscopy in the treatment of lunatotriquetral ligament injuries. Hand Clin 1995;11(1): $41-50$
16 Ritter MR, Chang DS, Ruch DS. The role of arthroscopy in the treatment of lunotriquetral ligament injuries. Hand Clin 1999; 15(3):445-454, viii viii

17 Ruch DS, Smith BP. Arthroscopic and open management of dynamic scaphoid instability. Orthop Clin North Am 2001;32(2): 233-240, vii vii

18 Park MJ, Ahn JH. Arthroscopically assisted reduction and percutaneous fixation of dorsal perilunate dislocations and fracturedislocations. Arthroscopy 2005;21(9):1153

19 Kim JP, Lee JS, Park MJ. Arthroscopic reduction and percutaneous fixation of perilunate dislocations and fracture-dislocations. Arthroscopy 2012;28(2):196-203.e2

20 Hudak PL, Amadio PC, Bombardier C; The Upper Extremity Collaborative Group (UECG). Development of an upper extremity outcome measure: the DASH (disabilities of the arm, shoulder and hand) [corrected]. Am J Ind Med 1996;29(6):602-608

21 MacDermid JC. Development of a scale for patient rating of wrist pain and disability. J Hand Ther 1996;9(2):178-183

22 Linscheid RL, Dobyns JH, Beabout JW, Bryan RS. Traumatic instability of the wrist. Diagnosis, classification, and pathomechanics. J Bone Joint Surg Am 1972;54(8):1612-1632

23 Youm Y, McMurthy RY, Flatt AE, Gillespie TE. Kinematics of the wrist. I. An experimental study of radial-ulnar deviation and flexion-extension. J Bone Joint Surg Am 1978;60(4):423-431

24 Knirk JL, Jupiter JB. Intra-articular fractures of the distal end of the radius in young adults. J Bone Joint Surg Am 1986;68(5):647-659

25 Geissler WB, Freeland AE, Savoie FH, McIntyre LW, Whipple TL. Intracarpal soft-tissue lesions associated with an intra-articular fracture of the distal end of the radius. J Bone Joint Surg Am 1996; 78(3):357-365

26 Slade JF III, Grauer JN, Mahoney JD. Arthroscopic reduction and percutaneous fixation of scaphoid fractures with a novel dorsal technique. Orthop Clin North Am 2001;32(2):247-261

27 Apergis E, Maris J, Theodoratos G, Pavlakis D, Antoniou N. Perilunate dislocations and fracture-dislocations. Closed and early open reduction compared in 28 cases. Acta Orthop Scand Suppl 1997;275:55-59

28 Melone CP Jr, Murphy MS, Raskin KB. Perilunate injuries. Repair by dual dorsal and volar approaches. Hand Clin 2000;16(3):439-448

29 Sauder DJ, Athwal GS, Faber KJ, Roth JH. Perilunate injuries. Hand Clin 2010;26(1):145-154

30 Souer JS, Rutgers M, Andermahr J, Jupiter JB, Ring D. Perilunate fracture-dislocations of the wrist: comparison of temporary screw versus K-wire fixation. J Hand Surg Am 2007;32(3):318-325

31 Trumble T, Verheyden J. Treatment of isolated perilunate and lunate dislocations with combined dorsal and volar approach and intraosseous cerclage wire. J Hand Surg Am 2004;29(3): 412-417

32 Slade JF, Lozano-Calderón S, Merrell G, Ring D. Arthroscopicassisted percutaneous reduction and screw fixation of displaced scaphoid fractures. J Hand Surg Eur Vol 2008;33(3):350-354

33 Toh S, Nagao A, Harata S. Severely displaced scaphoid fracture treated by arthroscopic assisted reduction and osteosynthesis. J Orthop Trauma 2000;14(4):299-302

34 Thornton GM, Johnson JC, Maser RV, Marchuk LL, Shrive NG, Frank CB. Strength of medial structures of the knee joint are decreased by isolated injury to the medial collateral ligament and subsequent joint immobilization. J Orthop Res 2005;23(5):1191-1198 